\title{
Ropivacaine in Peribulbar Anesthesia - Vasoconstrictive Properties
}

\author{
Catia Sousa Govêia, TSA 1, Edno Magalhães, TSA 2
}

Summary: Govêia CS, Magalhães E - Ropivacaine in Peribulbar Anesthesia - Vasoconstrictive Properties.

Background and objectives: Peribulbar anesthesia can reduce ocular blood flow (OBF) by increasing intraocular pressure (IOP) or due to the action of drugs. Ropivacaine has low toxicity and intrinsic vasoconstrictive properties, yet to be proven on the ocular vasculature. Measurements of ocular pulse amplitude (OPA) allow the indirect evaluation of the OBF. The objective of the present study was to evaluate through the OBF the vasoconstrictive properties of ropivacaine in peribulbar anesthesia.

Methods: Forty eyes undergoing peribulbar anesthesia with $7 \mathrm{~mL}$ of anesthetic solution without vasoconstrictor were randomly divided into two groups: ropivacaine $(n=20)$ and bupivacaine $(n=20)$. The IOP, ocular perfusion pressure (OPP), OPA, hemodynamic parameters, and the degree of akinesia before and 5 and 10 minutes after the blockade were evaluated. A dynamic contour tonometer was used to evaluate ocular parameters. Sedation was similar in both groups.

Results: A significant variation in hemodynamic parameters and intensity of the motor blockade was not observed between groups. Differences in IOP, OPP, and OPA ( $p<0.05)$ were observed between both groups at 5 and 10 minutes. The variation of IOP at 5 and 10 minutes was $-0.88 \%$ and $-4.54 \%$, respectively with ropivacaine, and $17.61 \%$ and $16.56 \%$ with bupivacaine. The change in OPP after 5 and 10 minutes was $1.5 \%$ and $4.2 \%$ with ropivacaine, and $-7 \%$ and $-6 \%$ with bupivacaine. Ocular pulse amplitude varied $-55.59 \%$ and $-59.67 \%$ with ropivacaine at 5 and 10 minutes, and $-34.71 \%$ and $-28.82 \%$ with bupivacaine.

Conclusions: Ropivacaine reduced more intensely the ocular pulse amplitude despite little changes in IOP and OPP. The reduction in ocular blood flow caused by ropivacaine can be attributed to its vasoconstrictive effect.

Keywords: ANESTHESICS, Local: ropivacaine; ANESTHESICS TECHNICS, Regional: peribulbar; MEASUREMENT TECHNICS: ocular pressure.

\section{INTRODUCTION}

Understanding the complex ocular anatomophysiology is extremely important for adequate anesthesia in ophthalmologic surgeries. Ocular dynamics can be affected by several maneuvers and drugs used in anesthesia.

Anesthetics can reduce intraocular pressure ${ }^{1}$. However, an increase in intraocular pressure due to the injection of large volumes of anesthetics can cause significant changes in ocular blood flow ${ }^{2}$.

Total ocular blood flow is the result of the sum of pulsatile and non-pulsatile components, and the former is responsible by ocular capillary perfusion ${ }^{3,4}$. Measurements of ocular pulsatile blood flow are based on pulsatile variations in intraocular pressure during the cardiac cycle and the resulting changes in ocular volumes ${ }^{5}$.

The effects of different types of anesthesia for ophthalmologic procedures on ocular hemodynamics are unknown.

Received from Universidade de Brasília - UnB.

1. Master's Degree, Assisting Professor in Surgery-Anesthesiology of the Faculdade de Medicina da Universidade de Brasília

2. PhD, Associated Professor of the Faculdade de Medicina da Universidade de Brasília

Submitted on March 9, 2010.

Approved on May 3, 2010.

Correspondence to:

Dra. Catia Sousa Govêia

SQSW 301 bloco H apto 405

70673108 - Brasília, DF, Brazil

E-mail: catia.goveia@gmail.com
Local anesthetics could affect vascular resistance by nervous block or direct effect. A definitive correlation between the neuronal blocking effects and the vascular effects of local anesthetics does not exist. Ropivacaine has almost the same anesthetic potency as bupivacaine, but this one causes vasodilation while that promotes vasoconstriction of capillaries and epidural blood vessels $6,7,8,9$. However, the response to drugs and stimuli vary in different vascular beds and the results should not be extrapolated to other tissues ${ }^{10,11}$.

Several authors have suggested that peribulbar anesthesia promotes a reduction in pulsatile ocular blood flow by pharmacologically-mediated changes in the vascular caliber, compression of the vasculature by the volume of anesthetic administered in the orbit, or by elevation of the intraocular pressure associated with a reduction in perfusion pressure ${ }^{12,13}$.

A reduction in ocular blood flow can be damaging to the eyes, especially in the presence of compromised ocular circulation, such as in patients with glaucoma or ischemic optic neuropathy 2,14 .

In peribulbar anesthesia, the profile of ropivacaine regarding latency and intensity of the motor blockade is similar to that of bupivacaine ${ }^{15}$. However, its vasoconstrictive effect on the ocular circulation remains unknown.

The objective of the present study was to compare the vasoconstrictive effect of peribulbar ropivacaine to bupivacaine on the ocular pulse amplitude. 


\section{METHODS}

This prospective, double-blind study was approved by the Ethics on Research Committee of the Faculdade de Medicina da Universidade de Brasília.

Forty eyes of adult patients of both genders, physical status I and II (ASA), with surgical ophthalmologic disorders that did not result from systemic diseases, scheduled for elective ophthalmologic surgeries under peribulbar anesthesia, were included in this study. Patients with diabetes, glaucoma, known bleeding disorders, on anti-hypertensive or anti-glaucoma medications, with a history of intolerance or allergy to any of the drugs involved in the study, were excluded. The size of the study population was chosen based on data available in the current literature 2,3,12,13,28,37.

Patients were monitored with precordial stethoscope, continuous electrocardiogram (ECGc), automatic non-invasive blood pressure (NIBP), and pulse oximetry $\left(\mathrm{SpO}_{2}\right)$. All patients received pre-anesthetic medication composed of midazolam 1 to $2 \mathrm{mg}$, associated with 10 or $20 \mu \mathrm{g}$ of intravenous fentanyl, and oxygen via nasal catheter at a flow of 2 L. $\mathrm{min}^{-1}$.

Patients were randomly divided in two groups using sequential sealed envelopes containing computer-generated random numbers. The target-group $(n=20)$ was called "Ropivacaine Group" and patients in this group underwent peribulbar anesthesia with an anesthetic solution containing $0.75 \%$ ropivacaine and 40 UTR. $\mathrm{mL}^{-1}$ of hialuronidase. The active control group ( $n=20$ ) was called "Bupivacaine Group", and its patients underwent peribulbar anesthesia with an anesthetic solution containing $0.75 \%$ bupivacaine and $40 \mathrm{UTR} \cdot \mathrm{mL}^{-1}$ of hialuronidase. Randomization and preparation of the syringes containing the anesthetic solution were done by a physician not involved with the patients. Syringes were prepared immediately before anesthesia and were identified with a label "study drug".

Sedation prior to the puncture was similar in both groups, with intravenous administration of $0.5 \mathrm{mg} \cdot \mathrm{kg}^{-1}$ of propofol.

Peribulbar anesthesia was performed with a $25 \times 7 \mathrm{~mm}$ needle and a fixed volume of $7 \mathrm{~mL}$ of the anesthetic solution, using the one-injection transpalpebral technique, laterally to the junction of the lateral third and medial two thirds of the inferior orbital border. External ocular pressure of $430 \mathrm{~g}$ was applied 1 minute after the peribulbar injection to favor orbital dispersion of the anesthetic solution.

Prior to anesthetic induction, control measurements of intraocular pressure, ocular perfusion pressure, ocular pulse amplitude, and mobility of the recti muscles of the eye to be anesthetized, as well as systolic, diastolic, and mean blood pressure, heart rate, and peripheral oxygen saturation, were performed.

The standardized technique using the dynamic contour digital tonometer (Pascal tonometer ${ }^{\mathrm{TM}}$, Ziemer Ophthalmic Systems, Switzerland) was used to measure intraocular pressure and ocular pulse amplitude. Measurements were performed on three moments: $\mathrm{M} 0$ = before peribulbar anesthesia; $\mathrm{M} 1=5$ minutes after the injection of the anesthetic solution; and M2 = 10 minutes after the injection. Ocular perfusion pressure was calculated applying the formula "ocular perfusion pressure = mean arterial pressure - intraocular pressure" ${ }^{16}$.
The dynamic contour tonometer has a concave contact surface, allowing the adaptation of the cornea and leading it to assume the naturally-presented shape, when the pressure is evenly distributed, with minimal distortion $17,18,19$. It is connected to a slit lamp and the microprocessor is capable of measuring the diastolic intraocular pressure and pulsatile fluctuations promoted by the cardiac cycle (ocular pulse amplitude).

The latency and quality of the motor blockade (degree of akinesia) were evaluated on the three moments established by observing the motility of each rectus muscle. The degree of motor palsy was evaluated according to the scale proposed by Nicoll et al. ${ }^{20}$, where the ocular globe is schematically divided in quadrants and the motor blockade of each quadrant is graded from 0 to 2 points as follows: $0=$ complete movement, 1 = partial movement, and 2 = absence of movement (akinesia). The intensity of the motor blockade of the extrinsic musculature of the eye is obtained by the sum of the quadrants, and it can vary from 0 to $8^{20}$. If after the study interval (10 minutes) the degree of akinesia were not enough, a new puncture through the medial caruncular approach with 2 to 3 $\mathrm{mL}$ of the anesthetic solution without adjuvant was performed to allow realization of the procedure.

Immediately after the evaluation phase, patients were transferred to the operating room for the surgical procedure; they were monitored continuously and received intravenous tenoxicam, $40 \mathrm{mg}$, for postoperative analgesia.

The investigator, who did not know the anesthetic solution used, was responsible for the administration of peribulbar anesthesia and evaluation of akinesia and hemodynamic parameters. Intraocular pressure and ocular pulse pressure were measured by two ophthalmologists.

The Kolmogorov-Smirnov test, Snedecor's F distribution, and Student $t$ test were used for the statistical analysis of unknown unequal variances. The Statistical Package for the Social Sciences (SPSS ${ }^{\mathrm{TM}}$ v. 11. SPSS Inc., USA) was used in the statistical analysis. A $p<0.05$ was considered statistically significant. The level of the confidence interval was $95 \%$.

\section{RESULTS}

Forty eyes of 38 patients undergoing surgery for pterygium associated with conjunctival auto-transplantation from September 2006 to January 2007 were evaluated.

The demographic characteristics of the patients were similar (Table I). Asthma, mild hypertension without the need for pharmacological therapy, and orthopedic problems were the main comorbidities.

The level of hemodynamic and respiratory parameters on the three moments can be seen in Table II. The variations in diastolic blood pressure did not reveal clinical significance.

Intraocular pressure monitoring did not show statistically significant differences between both groups before peribulbar anesthesia. The mean level in bupivacaine group before the blockade was $13.28 \pm 2.35 \mathrm{mmHg}$, while in the ropivacaine group it was $13.10 \pm 2.26 \mathrm{mmHg}$. Five minutes after the regional blockade, the intraocular pressure in bupivacaine group increased to 15.62 
Table I - Demographic Characteristics

\begin{tabular}{lll}
\hline & Bupivacaine & Ropivacaine \\
\hline $\begin{array}{l}\text { Age (years) } \\
\text { (mean } \pm \text { standard deviation) }\end{array}$ & $42.25 \pm 9.86$ & $39.2 \pm 10.27$ \\
$\begin{array}{l}\text { Weight (kg) } \\
\quad \text { (mean } \pm \text { standard deviation) }\end{array}$ & $63 \pm 10$ & $70 \pm 13 \mathrm{~kg}$ \\
Gender (male:female) & $5: 15$ & $12: 8$ \\
Physical status (ASA) - I : II & $16: 4$ & $19: 1$ \\
\hline
\end{tabular}

$\pm 4.31 \mathrm{mmHg}$, and it reduced to $12.98 \pm 2.71 \mathrm{mmHg}$ in ropivacaine group, representing a $17.61 \%$ variation in the first group and $-0.88 \%$ in the second. The difference between both groups was statistically significant $(p=0.026)$. Ten minutes after the peribulbar anesthesia, the intraocular pressure in bupivacaine group stabilized in $15.48 \pm 4.10 \mathrm{mmHg}$, a $16.56 \%$ variation regarding the initial measurement. However, the ropivacaine group showed further fall to $12.50 \pm 2.67 \mathrm{mmHg}$, a variation of $-4.54 \%$. At this moment, the difference in intraocular pressure in both groups was statistically significant $(p=0.01)$ (Figure 1).

Before anesthesia, the ocular perfusion pressure was 70.46 $\pm 8.52 \mathrm{mmHg}$ in bupivacaine group, and $70.55 \pm 9.0 \mathrm{mmHg}$ in ropivacaine group, which was not statistically significant. However, five minutes after the blockade, ocular perfusion pressure showed a reduction in bupivacaine group to $65.47 \pm 8.21 \mathrm{mmHg}$ (-7\% when compared to the previous measurement). The ropivacaine group showed a mean level of $71.61 \pm 7.11 \mathrm{mmHg}$, a $1.5 \%$ change when compared to the initial level. A statistically significant difference was observed between both groups ( $p=$ 0.016). At 10 minutes, the perfusion pressure remained close to previous levels in both groups, maintaining the statistical difference, with a mean of $65.91 \pm 7.63 \mathrm{mmHg}$ in bupivacaine group $(-6 \%)$, and $73.54 \pm 7.67 \mathrm{mmHg}$ in ropivacaine group $(4.2 \%)(p=$ 0.003) (Figure 2).

The ocular pulse amplitude before the peribulbar anesthesia was $1.7 \pm 0.63 \mathrm{mmHg}$ in the bupivacaine group, and 1.83 $\pm 0.73 \mathrm{mmHg}$ in the ropivacaine group, without statistically significant difference between both groups. A reduction in the ocular pulse amplitude was observed in both groups 5 minutes after the blockade, with $1.11 \pm 0.48 \mathrm{mmHg}$ in the bupivacaine group, and $0.81 \pm 0.27 \mathrm{mmHg}$ in the ropivacaine group, representing a significantly greater fall in the latter when compared to the former group $(p=0.022)$. The reduction regarding the first measurement was $-34.71 \%$ in the bupivacaine group, and $-55.59 \%$ in the ropivacaine group. At 10 minutes, the ocular pulse amplitude in the ropivacaine group was 1.21 $\pm 0.47 \mathrm{mmHg}$, while in the ropivacaine group it was $0.74 \pm$ $0.24 \mathrm{mmHg}$, showing a variation of -28.82 and $-59.67 \%$, respectively, regarding the initial levels, which was statistically significant $(p=0.001)$. Table III shows the results of the ocular pulse amplitude and 95\% confidence intervals. Figure 3 shows the variation in the ocular pulse amplitude.

The degree of motor blockade, assessed by the Nicoll scale, did not reveal significant differences between both groups, with a mode of 8 and 8 , for bupivacaine at 5 and 10 minutes, respectively, and 7 and 8 for ropivacaine.

Clinical adversities were not observed in any anesthesia in both groups.

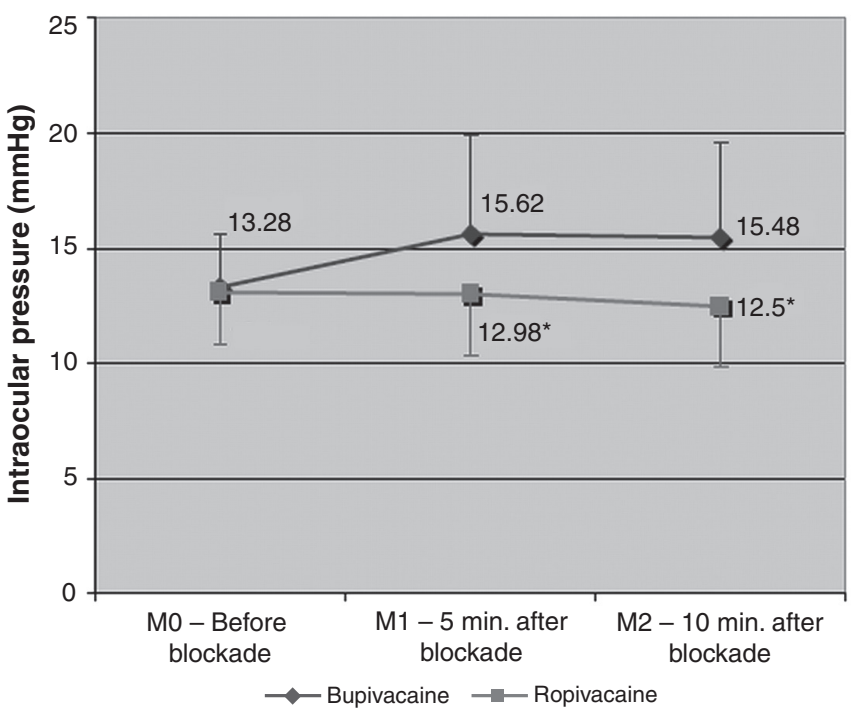

Figure 1. Variation of Intraocular Pressure. Mean \pm standard deviation. ${ }^{*} p<0.05$.

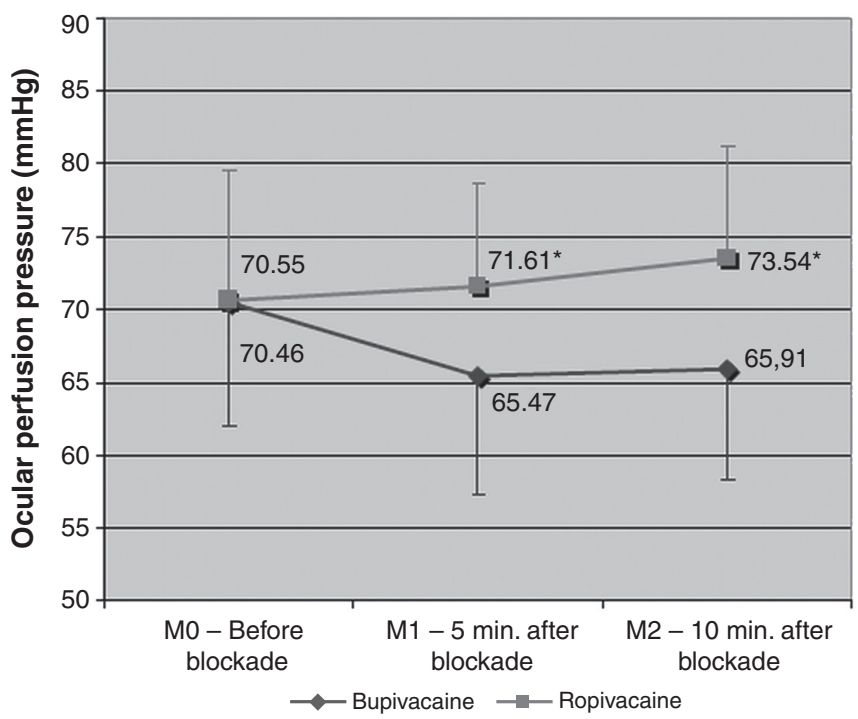

Figure 2. Changes in Ocular Perfusion Pressure. Mean \pm standard deviation. * $p<0.05$.

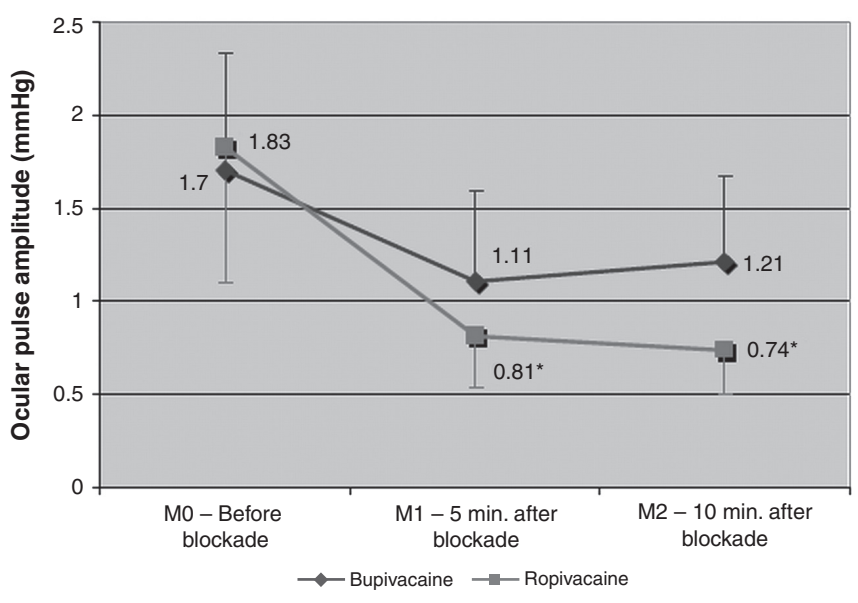

Figure 3. Variation in Ocular Pulse Amplitude. Mean \pm standard deviation. ${ }^{*} p<0.05$. 
Table II - Hemodynamic and Respiratory Parameters before and after Peribulbar Anesthesia.

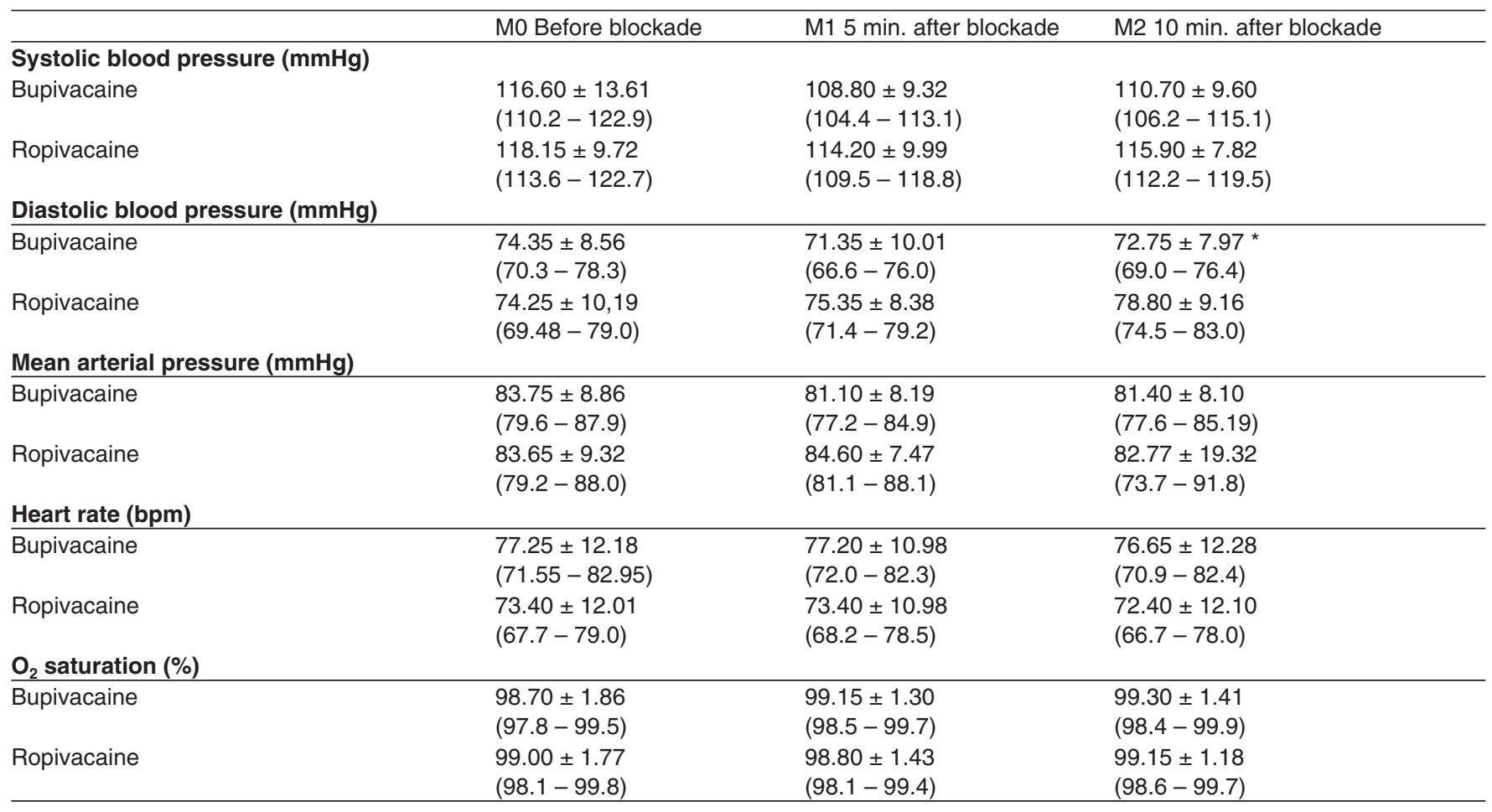

Mean \pm standard deviation. (95\% confidence interval) ${ }^{*} \mathrm{p}<0.05$.

Table III - Ocular Pulse Amplitude (OPA) before and after Peribulbar Anesthesia.

\begin{tabular}{|c|c|c|c|c|c|}
\hline & & & $\begin{array}{l}\text { T0 - Before } \\
\text { blockade }\end{array}$ & $\begin{array}{l}\mathrm{T} 1-5 \mathrm{~min} \text {. after } \\
\text { blockade }\end{array}$ & $\begin{array}{l}\text { T2 }-10 \text { min. after } \\
\text { blockade }\end{array}$ \\
\hline \multirow{4}{*}{$\begin{array}{l}\text { OPA } \\
(\mathrm{mmHg})\end{array}$} & & $\%$ variation & - & $-34.71 \%$ & $-28.82 \%$ \\
\hline & Ropivacaine & Mean \pm SD & $1.83 \pm 0.73$ & $0.81 \pm 0.27$ * & $0.74 \pm 0.24$ * \\
\hline & & $\%$ variation & _- & $-55.59 \%$ & $-59.67 \%$ \\
\hline & & $95 \% \mathrm{Cl}$ & $1.49-2.17$ & $0.68-0.94$ & $0.62-0.85$ \\
\hline
\end{tabular}

Mean \pm standard deviation (SD). Percentage variation in relation to moment zero. $95 \%$ confidence interval $(95 \% \mathrm{Cl}) .{ }^{*} \mathrm{p}<0.05$.

\section{DISCUSSION}

The ocular blood flow results from the sum of pulsatile and non-pulsatile components. The pulsatile component of the ocular blood flow is due to the entrance of blood during systole and reduction in the velocity of the diastolic blood flow, and it maintains better capillary and venous perfusion than the non-pulsatile component ${ }^{4}$. Pianka et al. ${ }^{3}$ suggested that the pulsatile blood flow has a relevant role in ocular perfusion and that reductions in this component could result in functional and morphological changes.

The quantitative evaluation of the blood flow is not easily obtained. The techniques used more often to study ocular blood flow include fluorescein angiography (non-quantitative), laser photo velocimetry (technically difficult), ultrasound with color Doppler (low reproducibility), radioactive microspheres (experimental and poorly adequate in humans), and measurements of the pulsatile component (ocular plethysmography) ${ }^{21}$.
Continuous recording of the intraocular pressure displays pressure modifications as a function of changes in ocular volume. Those variations due to blood inflow and outflow in the eye with every cardiac cycle are called "ocular pulse pressure waves" and it is assumed that they represent choroidal blood flow 19,22,23,24.

Determination of ocular pulsatile blood flow is one of the effective ways of clinically evaluating the choroidal blood flow. A few methods are used to evaluate the pulsatile blood flow through the analysis of the variations in the ocular pulse. The system developed by Langham and McCarthy uses a modified digital pneumotonometer. The dynamic contour tonometer calculates the pulse amplitude between ocular systolic and diastolic pulses ${ }^{25}$. The speed of evaluation, ease to use equipment, relatively low cost, reproducibility of the measurements, and the fact that they are not invasive are the advantages of those methods. The main limitation is due to the fact that the results represent indirect measurements of choroidal perfusion ${ }^{5,19}$. However, other authors have reported that both 
equipments are very useful to assess the variations in the same individual 26,27 .

Peribulbar anesthesia can interfere with ocular blood flow by different mechanisms. Findl et al. ${ }^{12}$ investigated the effects of peribulbar anesthesia with anesthetic solutions of lidocaine and bupivacaine on ocular hemodynamics of patients undergoing cataract extraction. Those authors observed that anesthesia led to a marked reduction in pulsatile ocular blood flow and attributed this effect not only to increases in intraocular pressure due to an increase in intraorbital volume, but also to pharmacological effects of local anesthetics. It is already known that a reduction in ocular perfusion pressure and the obstruction of venous drainage are responsible for the negative correlation between intraocular pressure and ocular blood flow. Nevertheless, subsequent studies observed that this change in ocular hemodynamics persists even after normalization of intraocular pressure. Several authors have suggested that the decrease in ocular blood flow after peribulbar anesthesia is mainly due to the direct vasomotor effects of local anesthetics 2,3,13,28.

Lidocaine and bupivacaine are known vasodilators. The possible explanation for the reduction of ocular blood flow can be provided by a study by Meyer, Flammer, and Luscher 29 who reported that, in pig cilliary arteries, lidocaine, bupivacaine, and mepivacaine interfere with the local mechanisms of vascular control, more specifically the production of endothelial-derived nitrous oxide leading to vasoconstriction.

Local and systemic dynamics of a specific local anesthetic depend on the site of administration. Thus, the different clinical applications should be considered separately. The lower cardiotoxicity of ropivacaine when compared to bupivacaine make it ideal for techniques of regional block which use large volumes, especially due to the elevated risk of accidental intravascular injection. However, ropivacaine is less lipid soluble and has a discrete lower potency than bupivacaine ${ }^{30,31}$. After epidural administration, the latency, extension of the sensorial blockade, and duration of the motor blockade of ropivacaine in higher concentrations are similar to those of bupivacaine, besides greater duration of analgesia ${ }^{32,33}$. A comparative study between equimolar concentrations of both local anesthetics in spinal anesthesia did not show differences in latency and duration of the sensorial blockade, but the motor blockade promoted by ropivacaine showed smaller duration and intensity ${ }^{34}$.

It has been suggested that in peribulbar anesthesia the differences in the potency of the motor blockade between both anesthetics could be concentration-dependent ${ }^{35}$. Comparison of different concentrations of ropivacaine in 68 patients showed that the concentration of $0.75 \%$ is preferable to $0.5 \%$ and $1.0 \%$, which produce, respectively, lower akinesia and prolonged anesthetic recovery ${ }^{36}$. Comparing peribulbar ropivacaine, racemic bupivacaine, and levobupivacaine, all in concentrations of $0.75 \%$, in 96 patients, significant differences regarding the quality of the motor blockade were not observed ${ }^{15}$. Equimolar concentrations of ropivacaine and bupivacaine in peribulbar anesthesia seem to have the same anesthetic potency.

Peribulbar ropivacaine and bupivacaine could have different effects in intraocular pressure. A study with 40 patients described that, despite similar blockade with analgesia and akinesia, $1 \%$ ropivacaine decreased the intraocular pressure immediately after its administration, unlike $0.75 \%$ bupivacaine, which promoted an initial elevation in intraocular pressure followed by a reduction. The authors suggested that the difference could be due to the vasoconstrictive action of ropivacaine ${ }^{50}$. However, one should take into consideration that comparing different concentrations of local anesthetics could affect the intensity of the motor blockade resulting in inaccurate evaluations of intraocular pressure.

Due to the similar characteristics in motor and sensitive blockade and its lower systemic toxicity, ropivacaine represents an effective alternative to bupivacaine in peribulbar anesthesia.

The literature does not have reports on the interference of peribulbar anesthesia with ropivacaine on the ocular pulse amplitude. The size of the sample in the present study was based in works that used similar technique 2,3,12,13,28,37.

The exclusion of patients with glaucoma and diabetes was based on the fact that both disorders interfere with ocular circulation, which could affect the study of the vasoconstrictive action of ropivacaine $4,38,39,40$.

Hemodynamic variations could be prejudicial for the correct evaluation of intraocular pressure and ocular blood flow. Blood pressure participates in the control of intraocular pressure; however, within the range of physiologic variation of the blood pressure, this role is relatively small ${ }^{41}$. The direct relationship between the elevation of the blood pressure and increase of the choroidal blood flow has been confirmed 42 . Thus, hemodynamic monitoring during the evaluation period of the study protocol was considered fundamental.

Both groups showed similar latency and quality of the blockade, with complete akinesia of the extraocular muscles at 5 and 10 minutes after the peribulbar anesthesia. The small elevation in intraocular pressure in bupivacaine group, although statistically different from ropivacaine group, was clinically insignificant and it did not achieve abnormal levels.

The Dynamic Contour Tonometer makes dynamic recording of the intraocular pressure and simultaneously evaluates the ocular pulse amplitude according to the inflow of blood in the eye during the cardiac systole. The tip of the tonometer has a curvature and diameter that adapts adequately to the cornea, the pressure sensor records and analyzes the signals in frequencies of $100 \mathrm{~Hz}$, and the microprocessor provides pressure and ocular pulse amplitude values ${ }^{43}$. The validity of the measurements provided by this device is equal to those observed with the standard device, the Goldmann Tonometer.

From the uninterrupted recording of intraocular pressure, the dynamic contour tonometer provides the value of the ocular pulse amplitude, in millimeters of mercury, according to the difference between systolic and diastolic pulses in the eye. Ease to handle and reproducibility of measurements are among the advantages of ocular plethysmographs. The disadvantages include the possibility of interference from several factors, including scleral rigidity, size of the eyes, and heart rate ${ }^{5,44}$. The more rigid the sclera, the lower is the distensibilty to the inflow of blood during systole, resulting in smaller 
pulse amplitude ${ }^{44}$. The axial length of the eye affects the ocular pulse amplitude. Myopic patients, who have greater axial length, show smaller values of pulsatile ocular blood flow 27,44. The heart rate shows an inverse relationship with ocular pulse amplitude ${ }^{45}$. In the present study, evaluations of the ocular blood flow were compared at different moments in the same individuals. This avoided that scleral rigidity and axial length of the eyes compromised analysis of the results.

The present protocol included observations at 5 and 10 minutes after peribulbar anesthesia. Important studies on the action of regional blocks on pulsatile blood flow performed measurements only until 5 minutes after the blockade 12,28,37. Other similar studies also performed evaluations only until 10 minutes $2,3,13$. Although it is possible that the effects of the reduction of the ocular pulse pressure are prolonged, the clinical character of the present study did not allow examinations beyond the preestablished 10 minutes.

In this study, the decision to evaluate intraocular pressure was based on the principle that it can interfere significantly with the ocular blood flow. The positive correlation between intraocular pressure and ocular pulse pressure, depending on the elastic properties of the sclera, has been reported. One study suggested that elevated levels of intraocular pressure would increase the tension in the bulbar wall, and the greater inflow of blood could result in an increase of the pressure in previously distended scleras ${ }^{44}$. On the other hand, an inverse relationship between intraocular pressure and ocular perfusion pressure has been observed. The difference between the pressure in the ophthalmic artery and the venous pressure represents the pressure gradient that maintains ocular perfusion. It is assumed that, in the eye, venous pressure is equal to intraocular pressure. Thus, the perfusion pressure can be represented by the difference between the mean arterial pressure and the intraocular pressure. In other words, the greater the intraocular pressure, the lower the ocular perfusion pressure and, consequently, smaller ocular blood flow 16,28,44.

Nevertheless, one should consider the presence of autoregulation in the ocular circulation. The decrease in perfusion pressure reduces the blood flow, but it could be counteracted by a decrease in vascular resistance. The mechanism that allows the decrease in resistance as a compensation for the reduction of perfusion pressure to maintain constant blood flow is called auto-regulation ${ }^{46}$. An elevated intraocular pressure could reduce ocular blood flow by modifying the ocular perfusion pressure in patients with compromised auto-regulation ${ }^{16}$. A study observed that, in volunteers, auto-regulation of the ocular pulse amplitude occurred in individuals with intraocular pressure in the 11 to 21 $\mathrm{mmHg}$ range. However, in monkeys with laser-induced glauco$\mathrm{ma}$, the elevation in intraocular pressure ( 30 to $35 \mathrm{mmHg}$ ) did not allow for auto-regulation and led to low pulse amplitude ${ }^{47}$. Very high intraocular pressures and glaucoma compromise auto-regulatory mechanisms. In the present study, preservation of the auto-regulation of ocular blood flow was considered an important factor in the study of the actions of ropivacaine on the ocular pulse amplitude. None of the patients evaluated had ocular vascular diseases and all presented normal levels of intraocular pressure and ocular pulse amplitude before anesthesia.
Both groups can be considered similar according to the demographic characteristics and basal levels of the parameters evaluated.

Systemic hemodynamic parameters did not show significant variations. Blood pressure and heart rate need to be constant in order for the pulsatile ocular blood flow to be a representative measure of ocular blood flow with ocular plethysmography ${ }^{48}$. In the present study, it was considered that small variations in blood pressure and heart rate in both groups did not interfere significantly with ocular changes.

The latency of peribulbar anesthesia was similar in both study groups. The short latency for maximal motor blockade in both groups in the present study is in accord to the report of previous works ${ }^{15,49}$. Peribulbar anesthesia can cause a temporary increase in the intraocular pressure due to the compressive effect of anesthetic solution on the eye and increase in intraorbital pressure. However, after the onset of akinesia - due to relaxation of extrinsic ocular musculature - a reduction in intraocular pressure is observed ${ }^{50}$. In the current study, the interference of the extraocular musculature on intraocular pressure was considered similar in both groups since all patients presented complete akinesia at 5 and 10 minutes after the blockade.

In the present study, despite the volume of $7 \mathrm{~mL}$ administered in the peribulbar approach, an important variation of intraocular pressure was not observed in bupivacaine group. A small increase, between $13 \mathrm{mmHg}$ and $15.6 \mathrm{mmHg}$ was observed without clinical significance, since the levels remained within normal limits. This increase, followed by a reduction of the intraocular pressure in bupivacaine group, is in agreement with other reports in the literature ${ }^{15,50}$. In ropivacaine group, a significant reduction or even a tendency towards stabilization of intraocular pressure was observed with values around $13 \mathrm{mmHg}$ in all measurements. Those results also confirm the findings of other authors who have reported the absence of an increase in this parameter after peribulbar anesthesia with ropivacaine ${ }^{51}$. The difference between both groups observed in the present study, as well as suggested by Nociti et al. ${ }^{50}$, could be due to the intrinsic vasoconstrictive property of ropivacaine.

The significant reduction in ocular pulse amplitude observed after the peribulbar anesthesia in both groups is also endorsed by with other studies on this subject. A study of 22 eyes under peribulbar anesthesia with equal parts of $2 \%$ lidocaine and $0.5 \%$ bupivacaine without vasoconstrictors demonstrated an increase in intraocular pressure and a significant reduction of the pulsatile ocular blood flow. However, the decrease in the flow persisted despite the regularization of the intraocular pressure 5 minutes after the blockade, representing a possible vasoconstrictor effect of local anesthetics on ocular hemodynamics ${ }^{12}$.

Other studies on peribulbar anesthesia with equal volumes of $2 \%$ lidocaine and $0.5 \%$ bupivacaine without vasoconstrictors confirmed the report of Findl et al. ${ }^{12}$. Chang et al. ${ }^{2}$ compared the technique of peribulbar anesthesia with subconjunctival block; the reduction of pulsatile ocular flow in the first group was attributed to the pharmacological effects of the anesthetic solution. Retrobulbar block, which uses a smaller volume of local anesthetic, caused temporary elevation of the intraocular pressure 
and persistent reduction of the ocular pulsatile flow similar to the peribulbar technique in a study in 20 eyes ${ }^{13}$. The authors of the study that compared peribulbar to parabulbar anesthesia in 40 patients did not observe changes in intraocular pressure due to the small volume of anesthetics administered and attributed to $2 \%$ lidocaine the responsibility for the reduction in ocular pulse amplitude ${ }^{3}$. Lung et al. ${ }^{28}$ compared two volumes of anesthetic solution in peribulbar anesthesia and the group that used the smaller volume showed less reduction in the parameter of ocular hemodynamics, corroborating the theory of pharmacological action. The results of those studies are not comparable to the present study, since they used different anesthetics and volumes, but it is apparent that peribulbar anesthesia is related to the reduction in pulsatile ocular blood flow due to the effects of the local anesthetics.

Nevertheless, in the present study, the magnitude of reduction in ocular pulse amplitude produced by ropivacaine $(60 \%)$ was significantly more accentuated than that produced by bupivacaine $(29 \%)$. In the studies that evaluated the effects of peribulbar block on the ocular blood flow, the decrease in the ocular pulsatile flow was attributed to bupivacaine, which causes vasodilation in other capillary beds ${ }^{2,12,13,28}$. Ropivacaine has a proven intrinsic vasoconstrictor activity in other capillary beds ${ }^{6,7}$. It is quite possible that, in the present study, the vasoconstrictor actions of ropivacaine were responsible for the more intense reduction in ocular blood flow.

Increases in intraocular pressure can decrease the ocular blood flow due to reduction in the ocular perfusion pressure and obstruction of venous drainage. The administration of anesthetics in the orbit could increase intraorbital and intraocular pressures, due to the compressive effect, as well as reduce the ocular blood flow ${ }^{2}$. However, in the present study, the intraocular pressure did not show significant changes but, despite this, a reduction in ocular pulse amplitude was observed. The effect was more pronounced in the group of patients who received ropivacaine, in whom were observed a decrease in intraocular pressure concomitant to the intense reduction in ocular pulsatile flow. Once more, attributing the reduction in ocular blood flow to the vasoconstrictor activity of ropivacaine, and not to intraocular pressure, is justified.

In general, fluctuations in mean arterial pressure show greater magnitude than those of intraocular pressure. Thus, mean arterial pressure is, comparatively, a more important factor than intraocular pressure in variations in the ocular perfusion pressure and ocular blood flow. A large elevation in the intraocular pressure would be necessary to interfere significantly with the ocular blood flow in healthy individuals ${ }^{16}$. In the present study, significant variations in systemic blood pressure or intraocular pressure were not observed. Therefo$r e$, it is believed that those parameters did not cause important interference on the ocular pulse amplitude.

The administration of local anesthetics did not induce important systemic hemodynamic variations. Thus, the changes observed in ocular blood flow probably are not related to physiological changes caused by the systemic actions of local anesthetics. Ocular perfusion pressure depends on mean arterial pressure and intraocular pressure, and it varied very lit- tle, as well as the other two parameters, in both study groups. A statistically significant difference was observed between groups, but the absolute variation does not seem to have important clinical significance. The ocular perfusion pressure decreased with bupivacaine, from approximately $70 \mathrm{mmHg}$ to $66 \mathrm{mmHg}$. In ropivacaine group, this pressure showed a tendency for stabilization, from approximately $70 \mathrm{mmHg}$ to 73 $\mathrm{mmHg}$. Patients in bupivacaine group exhibited a moderate reduction in ocular pulse amplitude, differently from those in ropivacaine group, who manifested a significant reduction in the pulsatile ocular flow. Since ropivacaine group presented smaller ocular pulse amplitude associated with maintenance of ocular perfusion pressure, this reinforces the hypothesis of pharmacologically-mediated vasoconstriction.

The ocular blood flow depends not only on the difference between arterial and venous pressure, but also on the local vascular resistance. The intraocular pressure and ocular perfusion pressure were maintained in the patients evaluated in this study. The most likely mechanism to explain the reduction in pulsatile ocular blood flow involves modification of intraorbital vasculature resistance due to the action of those local anesthetics.

Possible mechanisms for the vasoconstrictor action of local anesthetics remain unknown. Direct activity of pre- and post-capillary smooth muscle ${ }^{10}$, indirect release or blockade of release of vasoactive substances, blockade or activation of adrenergic receptors, and reduction in metabolic demand have been suggested $11,52,53,54$. However, none of those mechanisms seemed to be consistent. Changes in cytoplasmic calcium, activation of lipoxigenase pathways, and differences in stereoisomerism between ropivacaine and racemic bupivacaine may play a role in the vasoactive effect of those anesthetics $11,54,55,56$. The intracellular increase in calcium ions is the initial stimulus for the contraction of smooth muscle fiber and it can occur by stretching, nervous or hormonal stimulation, and chemical changes in the environment of the fiber 57. Some specific kinases (protein kinase C, Rho-kinase, and p44/42 mitogen-activated protein kinase) involved in calcium release process and contractile activation of smooth muscle contribute as mediators of ropivacaine-induced contraction in rat aortic smooth muscle ${ }^{55}$.

The smooth muscle fibers have important diversity in how they contract or relax in face of different substances or transmitters. In different locations, the same substance can promote contraction or relaxation of the smooth muscle fiber ${ }^{57}$. Vasodilator properties of lidocaine on human skin involve the blockade of conduction in sympathetic nerves and the release of nitrous oxide by the vascular endothelium ${ }^{58}$. On the other hand, in isolated pig cilliary arteries, the role of local anesthetics lidocaine, bupivacaine, and mepivacaine on vascular control mechanisms and on action of endothelium-dependent relaxation factors seems to be different. Meyer, Flammer, and Luscher ${ }^{29}$ reported that local anesthetics blocked endothelial production of nitrous oxide and that the compromise of endothelial relaxation mechanism can present a significant contribution in the decrease of the blood flow after intraorbital anesthesia. Nevertheless, in the present study, ropivacaine promoted more intense change in ocular hemodynamics than 
bupivacaine. It is possible that this effect would be secondary to the intrinsic vasoconstrictor activity of ropivacaine besides the interaction with the vascular endothelium of ocular circulation, as suggested by Meyer, Flammer, and Luscher 29.

Auto-regulation is observed in retinal blood flow. However, are controversies on its presence in the choroid $4,28,59$. Studies have reported the presence of auto-regulatory mechanisms in the choroid, possibly neurogenic or passive ${ }^{46,59}$. It is assumed that auto-regulation is, at best, modest in the choroid ${ }^{4,13}$. It should be emphasized that using measurements of ocular pulse amplitude one can evaluate choroidal blood flow, the main component of pulsatile ocular blood flow. In the present study, it is unlikely that the auto-regulatory mechanisms of compensation of the choroidal blood flow had somehow influenced more one group than the other.

Among the limitations of the present study is the fact that this study did not evaluate the axial length of anesthetized eyes, which is known to influence the measurements of ocular pulse amplitude ${ }^{27,44}$. Comparisons were undertaken in both groups, in the same individuals, at different moments, which reduced the interference of axial ocular length on the evaluation of pulsatile ocular blood flow.

Measurement of ocular pulse amplitude is an indirect method of evaluating the ocular blood flow, and for this reason it could be considered a limitation of this study. However, there are very few non-invasive clinical methods to study the choroidal blood flow as effective as the techniques that evaluate pulsatile ocular blood flow ${ }^{21}$. Besides, the ocular pulse amplitude only measures the pulsatile blood flow, without quantifying the total ocular blood flow. It is known that the pulsatile component corresponds to $50 \%-80 \%$ of the total blood flow ${ }^{48}$, but the non-pulsatile, or diastolic, component cannot be evaluated by this method ${ }^{21}$. It has been suggested that vasoconstriction could increase local diastolic pressure and alter the proportion of non-pulsatile blood flow. Thus, plethysmographic measurements, which depend on the pulsatile component, would underestimate the ocular blood flow. It is possible that the increase in non-pulsatile blood flow would compensate the reductions in the pulsatile component ${ }^{60}$.

The clinical nature of the present study prevented the evaluation of changes in ocular hemodynamics for a period longer than 10 minutes to avoid further delays in the surgery. Although one study on the effects of retrobulbar block on ocular blood flow using Doppler demonstrated prolonged effects of $2 \%$ lidocaine with 1:200,000 adrenaline even after the end of the surgery ${ }^{61}$, in the present study, other postoperative evaluations were not undertaken. Patients were transferred to the operating room immediately after the protocol was performed and received, according to their needs, other drugs that could interfere with subsequent evaluations of the parameters being investigated.

Very few reports in the literature on peribulbar anesthesia have studied the vasoconstrictive properties of ropivacaine.
Nicholson, Sutton, and Hall 62 investigated peribulbar ropivacaine and suggested, although without pharmacokinetic assessment, that its vasoconstrictor effect could reduce systemic absorption, resulting in lower plasma concentrations. On the other hand, bupivacaine, which is a vasodilator, could lead to greater plasma concentrations and potential systemic toxicity. Nevertheless, Huha et al. ${ }^{35}$ demonstrated that the lower liposolubility of ropivacaine favors plasma levels relatively higher than bupivacaine. The lower levels of intraocular pressure were attributed to the vasoconstrictor effects of ropivacaine, when compared to bupivacaine, in the study by Nociti et al. ${ }^{50}$ However, the authors did not evaluate other parameters that could have proven this hypothesis. The present study is, possibly, the first to analyze the action of ropivacaine on the ocular blood flow and to demonstrate the effects of its vasoconstrictive property through the peribulbar approach, demonstrating that it is capable of reducing the ocular pulse amplitude in a higher magnitude than bupivacaine.

The reduction in ocular pulse amplitude could represent tissue hypoxia. In theory, there is a risk of functional and morphological damage, compromising the visual field and with loss of nerve layers of the retina ${ }^{3}$. But it should be considered that the non-pulsatile blood flow is not evaluated by plethysmography and that it could maintain an adequate ocular perfusion ${ }^{37,60}$. Besides, the magnitude of the reduction of the local blood flow capable of affecting cellular function remains unknown. Important decreases in blood flow in peripheral nerves of rats caused by ropivacaine did not lead to histopathological changes suggestive of peripheral neurotoxicity ${ }^{52}$. Nonetheless, reductions of ocular blood flow should be avoided in the presence of ocular vascular diseases. It has been suggested that the volume of peribulbar anesthetics in patients susceptible to decreases of ocular blood flow should be reduced ${ }^{28}$.

Ropivacaine is a local anesthetic adequate to be used in peribulbar anesthesia. It has a short latency, causes intense sensitive anesthesia and motor blockade, maintains intraocular pressure, and it presents low risk of toxic effects on the cardiovascular system. However, its vasoconstrictive properties promote intense reduction in ocular pulse amplitude. Therefore, it should be used with caution in regional blocks in patients with severe ocular diseases.

\section{CONCLUSION}

The magnitude of the reduction in ocular pulse amplitude promoted by ropivacaine was superior to that of bupivacaine and it was maintained for a period of 10 minutes despite minimal changes in intraocular pressure and ocular perfusion pressure. The reduction in ocular blood flow induced by ropivacaine translates the vasoconstrictor effect of this anesthetic when administered by the peribulbar approach. 
02. Chang BY, Hee WC, Ling R et al. - Local anaesthetic techniques and pulsatile ocular blood flow. Br J Ophthalmol, 2000;84:1260-1263.

03. Pianka P, Padova HW, Lazar M et al. - Effect of sub-Tenon's and peribulbar anesthesia on intraocular pressure and ocular pulse amplitude. J Cataract Refract Surg, 2001;27:1221-1226.

04. Harris A, Jonescu-Cuypers C, Kagemann L et al. - Atlas of ocular blood flow: vascular anatomy, pathophysiology, and metabolism. 1st Ed. Philadelphia, Butterworth-Heinemann, 2003;128.

05. Garzozi HJ, Shoham N, Chung HS et al. - Ocular blood flow measurements and their importance in glaucoma and age-related macular degeneration. Isr Med Assoc J, 2001;3:443-448.

06. Dahl JB, Simonsen L, Mogensen T et al. - The effect of $0.5 \%$ ropivacaine on epidural blood flow. Acta Anaesthesiol Scand, 1990;34:308-310.

07. Cederholm I, Evers E, Lofstrom JB - Skin blood flow after intradermal injection of ropivacaine in various concentrations with and without epinephrine evaluated by laser Doppler flowmetry. Reg Anesth, 1992;17:322-328.

08. Ishiyama $\mathrm{T}$, Dohi $\mathrm{S}$, lida $\mathrm{H}$ et al. - The effects of topical and intravenous ropivacaine on canine pial microcirculation. Anesth Analg, 1997;85:75-81.

09. Wienzek H, Freise H, Giesler I et al. - Altered blood flow in terminal vessels after local application of ropivacaine and prilocaine. Reg Anesth Pain Med, 2007;32:233-239.

10. Kopacz DJ, Carpenter RL, Mackey DC - Effect of ropivacaine on cutaneous capillary blood flow in pigs. Anesthesiology, 1989;71:69-74.

11. lida $\mathrm{H}$, Watanabe $\mathrm{Y}$, Dohi $\mathrm{S}$ et al. - Direct effects of ropivacaine and bupivacaine on spinal pial vessels in canine: assessment with closed spinal window technique. Anesthesiology, 1997;87:75-81.

12 Findl O, Dallinger S, Menapace R et al. - Effects of peribulbar anesthesia on ocular blood flow in patients undergoing cataract surgery. Am J Ophthalmol, 1999;127:645-649.

13. Watkins R, Beigi $B$, Yates $M$ et al. Intraocular pressure and pulsatile ocular blood flow after retrobulbar and peribulbar anaesthesia. $\mathrm{Br} J$ Ophthalmol, 2001;85:796-798.

14. Calenda E, Rey N, Compere V et al. - Peribulbar anesthesia leading to central retinal artery occlusion. J Clin Anesth, 2009;21:311-312.

15. Magalhães E, Govêia CS, Oliveira KB - Bupivacaína racêmica, levobupivacaína e ropivacaína em anestesia loco regional para oftalmologia: um estudo comparativo. Rev Assoc Med Bras, 2004;50:195-198.

16. Hayreh SS - Blood flow in the optic nerve and factors that may influence it. Prog Retin Eye Res, 2001;20:595-624.

17. Kaufmann C, Bachmann LM, Thiel MA - Comparison of dynamic contour tonometry with Goldmann applanation tonometry. Invest Ophthalmol Vis Sci, 2004;45:3118-3121.

18. Hanratty $M-$ The dynamic Pascal contour tonometer. Optician, 2004;22:4.

19. Erickson DH, Goodwin D, Rollins M et al. - Comparison of dynamic contour tonometry and Goldmann applanation tonometry and their relationship to corneal properties, refractive error, and ocular pulse amplitude. Optometry, 2009;80:169-174.

20. Nicoll JM, Treuren B, Acharya PA et al. - Retrobulbar anesthesia: the role of hyaluronidase. Anesth Analg, 1986;65:1324-1328.

21. Bosley TM, Cohen MS, Gee W et al. - Amplitude of the ocular pneumoplethysmography waveform is correlated with cardiac output. Stroke, 1993;24:6-9.

22. Alm A, Bill A - Ocular and optic nerve flow at normal and increased intraocular pressure in monkeys (Macaca irus): a study with radioactive labelled microespheres including flow determination in brain and some other tissues. Exp Eye Res, 1973;15:15.

23. OBrien C, Harris A - Optic nerve blood flow measurement. Em: Yanoff $\mathrm{M}$ et al. Ophthalmology. $2^{\text {nd }}$ Ed. Philadelphia: Mosby, 2004.

24. Nicolela MT - Fluxo sanguíneo ocular em glaucoma: métodos de avaliação e importância. Arq Bras Oftamol, 1997;60:639-649.

25. Langham ME, McCarthy E - A rapid pneumatic applanation tonometer: comparative findings and evaluation. Arch Ophthalmol, 1968;79:389-399.

26. Krakau CET - Calculation of the pulsatile ocular blood flow. Invest Ophthalmol Vis Sci, 1992;33:2754-2756.

01. Donlon JV, Doyle DJ, Feldman MA - Anesthesia for Eye, Ear, Nose, and Throat Surgery. Em: Miller RD et al. Anesthesia, 6th Ed. Philadelphia, Churchill Livingstone, 2005;3376.

27. Mori F, Konno S, Hikichi T et al. - Factors affecting pulsatile ocular blood flow in normal subjects. Br J Ophthalmol, 2001;85:529-532. 
28. Lung S, Luksch A, Weigert G et al. - Influence of infusion volume on the ocular hemodynamic effects of peribulbar anesthesia. J Cataract Refract Surg, 2006;32:1509-1512.

29. Meyer P, Flammer J, Luscher TF - Local anesthetic drugs reduce endothelium-dependent relaxation of porcine ciliary arteries. Invest Ophthalmol Vis Sci, 1993;34:2730-2736.

30. Burke D, Joypaul V, Thomson MF - Circumcision supplemented by dorsal penile nerve block with $0.75 \%$ ropivacaine: a complication. Reg Anesth Pain Med, 2000;25:424-427.

31. Brockway MS, Bannister J, McClure JH et al. - Comparison of extradural ropivacaine and bupivacaine. $\mathrm{Br} \mathrm{J}$ Anaesth, 1991;66:31-37.

32. Katz J, Feldman MA, Bass EB et al. - Adverse intraoperative medical events and their association with anesthesia management strategies in cataract surgery. Ophthalmology, 2001;108:1721-1726. Apud: Ripart J, Nouvellon E, Chaumeron A. Regional anesthesia for eye surgery. Reg Anesth Pain Med, 2005;30:72-82.

33. Wood MB, Rubin AP - A comparison of epidural $1 \%$ ropivacaine and $0.75 \%$ bupivacaine for lower abdominal gynaecological surgery. Anesth Analg, 1993;76:1274-1278.

34. Griffin RP, Reynolds F - Extradural anaesthesia for caesarian section: a double-blind comparison of $0.5 \%$ ropivacaine and $0.5 \%$ bupivacaine. Br J Anaesth, 1995; 74:512-516.

35. Huha T, Ala-Kokko TI, Salomaki T et al. - Clinical efficacy and pharmacokinetics of $1 \%$ ropivacaine and $0.75 \%$ bupivacaine in peribulbar anaesthesia for cataract surgery. Anaesthesia, 1999;54:137-141.

36. Gioia L, Fanelli G, Casati A et al. - A prospective, randomized, doubleblinded comparison of ropivacaine $0.5 \%, 0.75 \%$, and $1 \%$ ropivacaine for peribulbar block. J Clin Anesth, 2004;16:184-188.

37. Hulbert MF, Yang YC, Pennefather PM et al. - Pulsatile ocular blood flow and intraocular pressure during retrobulbar injection of lignocaine: influence of additives. J Glaucoma, 1998;7:413-416.

38. Grunwald JE, Piltz J, Hariprasad SM et al. - Optic nerve and choroidal circulation in glaucoma. Invest Ophthalmol Vis Sci, 1998;39:2329-2336.

]39. Fuchsjager-Mayrl G, Wally B, Georgopoulos M et al. - Ocular blood flow and systemic blood pressure in patients with primary open angle glaucoma and ocular hypertension. Invest Ophthalmol Vis Sci, 2004; $45: 834-839$

40. Schmidt KG, von Ruckmann A, Kemkes-Matthes B et al. - Ocular pulse amplitude in diabetes mellitus. Br J Ophthalmol, 2000;84:1282-1284.

41. Murphy DF - Anesthesia and intraocular pressure. Anesth Analg, 1985;64:520-530.

42. Polak K, Polska E, Luksch A et al. - Choroidal blood flow and arterial blood pressure. Eye, 2003;17:84-88.

43. Hoffmann EM, Grus FH, Pfeiffer N - Intraocular pressure and ocular pulse amplitude using dynamic contour tonometry and contact lens tonometry. BMC Ophthalmology, 2004;4:1-7.

44. Kaufmann C, Bachmann LM, Robert YC et al. - Ocular pulse amplitude in healthy subjects as measured by dynamic contour tonometry. Arch Ophthalmol, 2006;124:1104-1108.

45. Trew DR, James CB, Thomas $\mathrm{SH}$ et al. - Factors influencing the ocular pulse: the heart rate. Graefes Arch Clin Exp Ophthalmol, 1991;229:553-556. Apud: Kaufmann C et al. - Ocular pulse amplitude in healthy subjects as measured by dynamic contour tonometry. Arch Ophthalmol, 2006;124:1104-1108.

46. Riva CE, Titze P, Hero M et al. - Effect of acute decreases of perfusion pressure on choroidal blood flow in humans. Invest Ophthalmol Vis Sci, 1997;38:1752-1760.

47. Mittag TW, Serle J, Schumer R et al. - Studies of the ocular pulse in primates. Surv Ophthalmol, 1994;38:183-190.

48. Schmetterer L, Dallinger S, Findl O et al. -Noninvasive investigations of the normal ocular circulation in humans. Invest Ophthalmol Vis Sci, 1998;39:1210-1220.

49. Nociti JR, Serzedo PS, Zuccolotto EB et al. - Ropivacaine in peribulbar block: a comparative study with bupivacaine. Acta Anaesthesiol Scand, 1999;43:799-802.

50. Nociti JR, Serzedo PS, Zuccolotto EB et al. - Intraocular pressure and ropivacaine in peribulbar block: a comparative study with bupivacaine. Acta Anaesthesiol Scand, 2001;45:600-602.
51. Serzedo PS, Nociti JR, Zuccolotto EB et al. - Bloqueio peribulbar com Ropivacaína: influência da hialuronidase sobre a qualidade do bloqueio e a pressão intraocular. Rev Bras Anestesiol, 2001;51:202-207.

52. Bouaziz H, lohom G, Estebe JP et al. - Effects of levobupivacaine and ropivacaine on rat sciatic nerve blood flow. $\mathrm{Br} J$ Anaesth, 2005;95:696-700.

53. Martins CA, Aragão PW, Freire SM et al. - Efeito da ropivacaína na recaptação neuronal de noradrenalina em músculo liso. Rev Bras Anestesiol, 2005;55:532-537.

54. lida $\mathrm{H}$, Ohata $\mathrm{H}$, lida $\mathrm{M}$ et al. - The differential effects of stereoisomers of ropivacaine and bupivacaine on cerebral pial arterioles in dogs. Anesth Analg, 2001;93:1552-1556.

55. Yu J, Tokinaga $Y$, Kuriyama $\mathrm{T}$ et al. - Involvement of $\mathrm{Ca}^{2+}$ sensitization in ropivacaine-induced contraction of rat aortic smooth muscle. Anesthesiology, 2005;103:548-555.

56. Sung HJ, Sohn JT, Park JY et al. - Direct effect of ropivacaine involves lipoxygenase pathway activation in rat aortic smooth muscle. Can J Anaesth, 2009;56:298-306.

57. Guyton AC, Hall JE - Tratado de fisiologia médica. Cap. 8. 11를 Ed. Rio de Janeiro, Elsevier, 2006.

58. Newton DJ, McLeod GA, Khan F et al. - Mechanisms influencing the vasoactive effects of lidocaine in human skin. Anaesthesia, 2007;62:146-150.

59. Riva CE, Titze $P$, Hero $M$ et al. - Choroidal blood flow during isometric exercises. Invest Ophthalmol Vis Sci, 1997;38:2338-2343.

60. Bosem ME, Lusky M, Weinreb RN - Short-term effects of levobunolol on ocular pulsatile flow. Am J Ophthalmol; 1992;114:280-286.

61. Huber KK, Remky A - Effect of retrobulbar versus subconjunctival anesthesia on retrobulbar hemodynamics. $\mathrm{Br} \mathrm{J}$ Ophthalmol, 2005;89:719-723.

62. Nicholson G, Sutton B, Hall GM - Ropivacaine for peribulbar anesthesia. Reg Anesth Pain Med, 1999;24:337-340.

Resumen: Goveia CS, Magalhães E - Anestesia Peribulbar con Ropivacaína - Estudio de la Acción Vasoconstrictora.

Justificativa y objetivos: La anestesia peribulbar puede reducir el flujo sanguíneo ocular (FSO) por elevación de la presión intraocular (PIO) o por la acción de fármacos. La ropivacaína tiene una baja toxicidad y una acción vasoconstrictora intrínseca que todavía no ha sido comprobada sobre la vasculatura ocular. Medidas de la amplitud del pulso ocular (APO) permiten una evaluación indirecta del FSO. El objetivo de este estudio es evaluar, vía FSO, la acción vasoconstrictora de la ropivacaína en la anestesia peribulbar.

Método: Cuarenta pacientes, sometidos a bloqueo peribulbar con 7 $\mathrm{mL}$ de solución anestésica, sin vasoconstrictor, fueron divididos aleatoriamente en dos grupos: Ropivacaína $(n=20)$ y bupivacaína ( $n$ = 20). Se evaluaron PIO, presión de perfusión ocular (PPO), APO variables hemodinámicas y el grado de acinesia antes y a los 5 y 10 minutos posteriores al bloqueo peribulbar. Para la evaluación de los parámetros oculares, se utilizó el tonómetro de contorno dinámico. La sedación fue idéntica en los dos grupos.

Resultados: No se registró variación significativa de los parámetros hemodinámicos y de la intensidad del bloqueo motor. A los 5 y 10 minutos, se registró una diferencia de PIO, PPO y APO entre los grupos $(p<0,05)$. La variación de la PIO a los 5 y 10 minutos fue, respectivamente, de $-0,88 \%$ y $-4,54 \%$ con ropivacaína y de $17,61 \%$ y $16,56 \%$ con bupivacaína. La alteración de la PPO después de 5 y 10 minutos fue de $1,5 \%$ y $4,2 \%$ con ropivacaína, y de $-7 \%$ y $-6 \%$ con bupivacaína. La APO varió $-55,59 \%$ y $-59,67 \%$ con ropivacaína a los 5 y 10 minutos, y $-34,71 \%$ y $-28,82 \%$ con bupivacaína.

Conclusiones: La ropivacaína redujo más intensamente la amplitud del pulso ocular, a pesar de las pequeñas alteraciones de PIO y PPO. La disminución del flujo sanguíneo ocular por la ropivacaína puede ser atribuida a su efecto vasoconstrictor. 